\title{
CONSIDERAÇÕES SOBRE OS CONCEITOS DE LINGUAGEM, MÉTODO E VERDADE NO PRÓLOGO EPISTEMOLÓGICO-CRÍTICO DA OBRA ORIGEM DO DRAMA BARROCO ALEMÃO DE WALTER BENJAMIN
}

Tiago Rodrigues Araújo

\begin{abstract}
RESUMO
Este artigo tem como pretensão entender o desenvolvimento dos conceitos linguagem, método e verdade no prólogo epistemológico - crítico da obra Origem do Drama Barroco alemão. Dada a grande importância desse texto bem como a sua relevância nos últimos anos, ficou notório o crescente interesse pelo pensamento filosófico de Walter Benjamin, sobretudo aqui no Brasil. Mas sem dúvida, suas considerações sobre a teoria do conhecimento, compõem uma das partes mais obscura de seu pensamento. Esse texto é muito mais que um simples prefácio à obra, mas é um texto em que Walter Benjamin investiga qual a tarefa da filosofia e sua relação com a verdade e o conhecimento.
\end{abstract}

Palavras-chave: Benjamin, linguagem, método, verdade, conhecimento.

\section{CONSIDERATIONS ABOUT THE CONCEPTS OF LANGUAGE, METHOD AND TRUTH IN THE CRITICAL-EPISTEMOLOGICAL PROLOGUE OF "THE ORIGIN OF GERMAN TRAGIC DRAMA" BY WALTER BENJAMIN}

\begin{abstract}
This article intends to understand the development of language, method and truth concepts in the critical-epistemological prologue in the work "The Origin of German Tragic Drama". Because of the importance of this text and its relevance in recent years, was notorious the growing interest in the philosophical writings of Walter Benjamin, especially here in Brazil. But, undoubtedly, his reflection on Theory of Knowledge, consists in one of the most obscure parts of his thought. The studied text is much more than a simple preface to the work, where Walter Benjamin leads the reader to an investigation that focuses on the task of philosophy and its relation with truth and knowledge.
\end{abstract}

Key-words: Benjamin, language, method, truth, knowledge. 
Este artigo tem como pretensão entender o desenvolvimento dos conceitos linguagem, método e verdade no prólogo epistemológico - crítico da obra Origem do Drama Barroco alemão. Logo no início do prefácio, Benjamin afirma que a questão da representação é própria à literatura filosófica, pois esta se apresenta como doutrina na sua forma acabada.

Tal doutrina assenta na codificação histórica. Benjamin recusa o modelo moderno de teoria do conhecimento e propõe sua superação além da transformação na ideia de uma filosofia como sistema, pois a verdade não se deixa apreender como posse de uma consciência.

É preciso buscar o que é essencial ao texto filosófico, à representação ${ }^{1}$. O texto filosófico confronta-se sempre com a questão da representação, mesmo em sua forma acabada como no caso da doutrina, pois a filosofia não depende do simples pensamento mas da codificação histórica. Segundo Benjamin, compreender a codificação histórica é compreender a teoria do conhecimento, a questão filosófica da verdade.

Para Benjamin, um texto filosófico não pode e nem deve ser entendido como um silogismo ou uma dedução matemática, porque a filosofia não é dedutiva e nem deve estar presa a um discurso lógico-formal. Nos textos filosóficos em que o caráter dedutivo é empregado, o caráter filosófico não deriva deste procedimento, pois este procedimento "matemático" pode significar a eliminação total do problema da representação.

Também é preciso um certo distanciamento do conceito de sistema, como teoria universalista por vezes até artificial e com um caráter remendado de sua

\footnotetext{
Não podemos nos abster de mencionar a polemica com relação a tradução de Darstellung, seja por apresentação ou representação. Optamos, neste texto, em mantermos a tradução feita por João Barrento, contudo citamos um artigo da J. M. Gagnebin que critica tal tradução. Diz ela: "o primeiro mal-entendido a ser dirimido é uma questão de tradução. A palavra Darstellung - utilizada por Benjamin para caracterizar a escrita filosófica - não pode, (aliás, nem deve), ser traduzida por "representação", como o faz Rouanet (que compreendeu perfeitamente o alcance do texto, conforme sua "Apresentação" muito esclarecedora demonstra, mas que o traduziu, às vezes, de maneira pouco precisa), nem o verbo darstellen pode ser traduzido por "representar". Mesmo que essa tradução possa ser legítima em outro contexto, ela induz, no texto em questão, a contrassensos, porque poderia levar à conclusão de que Benjamin se inscreve na linha da filosofia da representação - quando é exatamente desta, da filosofia da representação, no sentido clássico de representação mental de objetos exteriores ao sujeito, que Benjamin toma distância. Proponho, então, que se traduza Darstellung por "apresentação" ou "exposição", e darstellen por "apresentar" ou "expor", ressaltando a proximidade no campo semântico com as palavras Ausstellung (exposição de arte) ou também Darstellung, no contexto teatral (apresentação)."
} 
totalidade. Benjamin recusa o universalismo vazio do sistema que deve perder seu papel dominante para a determinação da verdade e da totalidade da experiência. A tarefa da filosofia, indica o autor, é uma atualização do conhecimento a partir da experiência com o real, com o presente, com o fenômeno, a partir de significativa do mundo das ideias.

Enquanto a filosofia ficar presa ao sistema não conseguirá ser a representação da verdade, pois para tal, a filosofia precisa se importar mais com a prática de sua forma. Esta prática, segundo o autor, está na forma do tratado "porque ele reenvia, ainda que apenas de forma latente, para os objetos da teologia, sem os quais não é possível pensar a verdade" ${ }^{2}$. É importante perceber aqui o quanto este texto é místico.

O tratado é uma representação como caminho não direto, esse é seu caráter metodológico. O tratado é a forma filosófica por excelência, pois seu método realiza uma dupla renúncia. Renuncia ao ideal filosófico do caminho reto e direto, em proveito dos desvios, e renuncia à obediência aos mandamentos da vontade subjetiva do autor, para recomeçar em torno da "coisa mesma", da realidade, uma vez que a filosofia deve insistir em outra prática do pensar, voltada para o presente, o real. Deste modo, para Benjamin, o método filosófico é o tratado, que como um mosaico

se compõe de elementos singulares e diferentes; nada poderia transmitir com mais veemência o impacto transcendente, quer da imagem sagrada, quer da verdade. $O$ valor dos fragmentos de pensamento é tanto mais decisivo quanto menos imediata é a sua relação com a concepção de fundo, e desse valor depende o fulgor da representação, na mesma medida em que o do mosaico depende da qualidade da pasta de vidro. ${ }^{3}$

Portanto, tanto o tratado como o mosaico, ambos "parentes - pois foram criações medievais - possuem a representação como caráter metodológico em que o pensamento volta ao princípio sempre de novo, através do método da contemplação. A representação contemplativa apoia as frases isoladas em uma sequência de pensamentos vacilantes e vagos com a intenção de fazer o leitor refletir.

\footnotetext{
2 BENJAMIN, Origem do drama trágico alemão, p. 16.

${ }^{3}$ Idem, p. 17.
}

Tiago Rodrigues Araújo - Professor efetivo de filosofia da E.E.F.M Elpídio de Almeida (João Pessoa - PB) Brasileiro, residente em João Pessoa - PB, E-mail: traraujof@gmail.com 
A representação contemplativa é o único estilo de escrita adequado à investigação filosófica, pois ela possui uma sabedoria prosaica, simples, mais ligada à vida, diferente do gesto imperativo da doutrina, e tendo objetos não muito grandiosos pois, quanto menor o objeto, maior a reflexão, já que seu objetivo não é levar o ouvinte ao entusiasmo mas à reflexão.

Segundo Benjamin, a representação como método próprio do tratado terá de ser representação das ideias. Pois a verdade, presente nas ideias representadas, furta-se da projeção no domínio do conhecimento, já que, para o autor, o conhecimento tem um caráter de posse, no qual a representação da verdade é secundária, pois para o conhecimento o método é um caminho para chegar ao objeto de apropriação.

Ou seja, segundo Benjamin, conhecimento é diferente de verdade. O objeto do conhecimento não coincide com a verdade, pois o conhecimento é questionável, mas a verdade não. Enquanto o conhecimento possui uma estrutura mediatizada por meio de conhecimentos isolados, a essência mesma da verdade, segundo Benjamin, é uma determinação absolutamente imediata e direta.

O conceito advém da espontaneidade do entendimento enquanto as ideias oferecem-se à contemplação, elas são algo já dado. Nesta distinção entre verdade e conhecimento, a ideia é definida como ser, e enquanto ser, tanto a ideia como a verdade alcançam o significado metafísico que é atribuído pelo sistema platônico, quando as ideias são salvas pela metafísica platônica.

É preciso salvar os fenômenos nas ideias, e os conceitos desenvolvem um papel mediador em que permitem que os fenômenos participem do ser das ideias. $E$ este papel mediador desenvolvido pelos conceitos permite a representação das ideias, tarefa que o autor considera primordial. Desse modo

\begin{abstract}
A salvação dos fenômenos por meio das ideias vai de par com a representação das ideias por meio da empiria. Pois as ideias não se representam em si mesmas, mas apenas e exclusivamente através de uma organização dos elementos coisais no conceito. E fazem-no sob a forma da configuração desses elementos. ${ }^{4}$
\end{abstract}

4 Idem, p. 22.

Tiago Rodrigues Araújo - Professor efetivo de filosofia da E.E.F.M Elpídio de Almeida (João Pessoa - PB) Brasileiro, residente em João Pessoa - PB, E-mail: traraujof@gmail.com 
Mas de que modo as ideias alcançam os fenômenos, já que os fenômenos não estão contidos nelas? Benjamin nos responde que é na representação das ideias que elas alcançam os fenômenos. Deste modo, os fenômenos não podem servir de critério para a existência das ideias. As ideias são "constelações eternas" e os fenômenos estão salvos nelas. Elas não são dadas no mundo dos fenômenos e seu ser não pode ser pensado como objeto de uma intuição.

A forma de se dar é própria da verdade que é desprovida de qualquer forma de intenção. Diz Benjamin, "a verdade nunca se manifesta em relação, e muito menos numa relação intencional. $O$ objeto de conhecimento determinado pela intencionalidade do conceito não é a verdade. A verdade é um ser não intencional formado por ideias" ${ }^{5}$. Deste modo, não há intuição na verdade, que em seu modo de ser - na ordem da ideia - é próxima do modo de ser simples das coisas, embora, como afirma Benjamin, a verdade seja superior às coisas simples pelo seu caráter de consistência e permanência. A verdade é a força da essência da empiria e o ser detentor desta força é o nome. ${ }^{6}$

O nome determina como são dadas as ideias, pois estas são da ordem da linguagem, da essência da palavra. Mas numa percepção primordial em que as palavras ainda não perderam sua aura em função do conhecimento. A ideia é da ordem da linguagem, está na essência da palavra, no seu momento simbólico.

A tarefa do filósofo é justamente recuperar, pela representação, o primado do caráter simbólico da palavra, na qual a ideia chega ao seu autoconhecimento, posto que "a ideia é algo de linguístico, um elemento simbólico presente na essência da palavra". Este autoconhecimento, segundo Benjamin, é o oposto de toda a comunicação orientada para o exterior, uma linguagem funcional.

\footnotetext{
5 Idem, p. 24.

${ }^{6}$ Vejamos o que nos diz Benjamin em outro texto bastante conhecido sobre a linguagem: "no âmbito da linguagem, 0 nome possui somente esse sentido e essa significação, de um nível incomparavelmente alto: ser a essência mais íntima da própria língua. O nome é aquilo através do qual nada mais se comunica, e em que a própria língua se comunica a si mesma, e de modo absoluto. No nome, a essência espiritual que se comunica é a língua. Somente onde a essência espiritual em sua comunicação for a própria língua em sua absoluta totalidade, somente ali estará o nome e lá estará o nome somente. Assim, como parte do legado da língua humana, o nome garante que a língua é pura e simplesmente a essência espiritual do homem; e é somente por isso que o homem é entre todos os seres dotados de espírito, o único cuja essência espiritual é plenamente comunicável" (Grifos do autor). Benjamin, W. Sobre a linguagem em geral e a linguagem do homem, in: Escritos sobre mito e linguagem, p. 56.
} 
Mas não cabe à filosofia fazer esta revelação, tal tarefa só cabe à rememoração que recupera a percepção primordial. Para Benjamin, na origem desta atitude está Adão, pois o ato adâmico de nomeação configura-se como o momento em que a linguagem ainda não tinha que lutar contra o significado comunicativo das palavras.

Na nomeação não há ainda uma intencionalidade e a contemplação filosófica é o lugar para renovar essa ideia, pois nesta renovação é possível reconstituir a percepção originária da palavra. A representação contemplativa é o único estilo de escrita adequado à investigação filosófica. Por conseguinte, a filosofia passou a ser o lugar de representação de algumas palavras com o objetivo último de sua contemplação.

A tarefa da filosofia é de representar as ideias para salvar os fenômenos. A forma do texto filosófico procura responder a forma da verdade, para além do domínio do conhecimento e da intencionalidade do sujeito, criando, assim, uma nova objetividade que não é nem científica e nem dedutiva, porque se constrói na elaboração de um discurso a partir da salvação dos fenômenos e da presentificação das ideias. Como diz Benjamin, "cada ideia é um sol, e relaciona-se com as outras como os sóis se relacionam uns com os outros".

A relação harmoniosa entre a música dessas essências é a verdade. A sua multiplicidade nomeada é finita" 7 . Ou seja, as ideias são finitas e descontinuas e qualquer tentativa de entender as ideias de outra forma vai fracassar como foi o caso, segundo Benjamin, do primeiro Romantismo, em que a verdade assumiu um caráter de consciência reflexiva em vez de assumir seu caráter de linguagem.

Para Benjamin, o drama trágico (Trauerspiel) é uma ideia, pensado a partir do ponto de vista do tratado de filosofia da arte. Este tratado, segundo o autor, se distingue do histórico-literário porque pressupõe uma unidade enquanto que o segundo propõe uma multiplicidade. Nesta unidade encontramos as diferenças e os extremos que a análise histórico-literária tende a esconder ou relativizar.

Para a filosofia da arte só os extremos são necessários, pois seja da forma ou do gênero, este extremo consiste na ideia. A linguagem será sempre um instrumento

\footnotetext{
7 BENJAMIN, Origem do drama trágico, p. 25-26.
} 
preciso se tomar como alusão a ideia, mas será enganador caso o filósofo se afaste da ideia assumindo como fundamento formal os conceitos.

Benjamin reformula a problemática discutida da seguinte maneira: "Como se

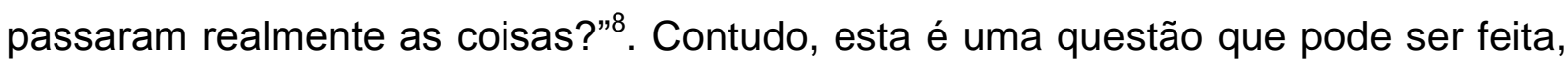
mas não é possível ser respondida. Todavia ela nos leva a outra questão que o autor intenciona concluir com o texto: "será possível decidir se a ideia é uma abreviatura indesejada ou se, pelo contrário, fundamenta por meio da sua expressão linguística o verdadeiro conteúdo científico" 9 . A palavra se despotencializa para encontrar sua realidade essencial na ideia. E é no mundo da ideia que a filosofia se desenvolve, e não na linha ininterrupta de deduções conceituais.

Cada ideia torna-se uma ideia primordial, que sempre reinicia o processo com uma nova ideia e desta forma as ideias seguem formando uma multiplicidade irredutível, finita, nomeadora que se oferece à contemplação.

A verdadeira contemplação rejeita o método dedutivo e salva os fenômenos na representação das ideias. Os fenômenos são abrigados através dos conceitos, nas ideias. Estas, só são representadas através de uma organização dos elementos coisais no conceito. É uma representação da verdade como caminho não direto, como desvio, método que Benjamin acredita ser o único possível para alcançar a verdade, tarefa do exercício filosófico. É preciso lembrar que, em várias passagens do prefácio, Benjamin opõe verdade e conhecimento. "A verdade é o equilíbrio tonal das essências - as ideias - na medida em que essas reconhecem os fenômenos.

No confronto da verdade - representada pelas ideias - com história, encontramos a origem. Mas, apesar de ser uma categoria histórica, a origem (Ursprung ) não tem nada em comum com a gênese (Entstehung). Diz Benjamin:

\footnotetext{
"Origem" não designa o processo de devir de algo que nasceu, mas antes aquilo que emerge do processo de devir e desaparecer. A origem insere-se no fluxo do devir como um redemoinho que arrasta no seu movimento o material produzido no processo de gêneses. O que é próprio da origem nunca se dá a ver no plano do fatual, cru e manifesto. O seu ritmo só se revela a um ponto de vista duplo, que o reconhece, por um lado como restauração e reconstituição, e por outro como algo de incompleto e inacabado". ${ }^{10}$
}

\footnotetext{
Idem, p. 30.

Idem, ibidem.

${ }^{10}$ Idem, p. 34.
}

Tiago Rodrigues Araújo - Professor efetivo de filosofia da E.E.F.M Elpídio de Almeida (João Pessoa - PB). Brasileiro, residente em João Pessoa - PB, E-mail: traraujof@gmail.com 
Desta maneira, é na origem ${ }^{11}$ que a ideia permanentemente se confronta com o mundo histórico até atingir a sua completude na totalidade da sua história. Desta forma, a origem se relaciona com a pré e pós história das ideias. A origem compõe o pondo de chegada do método próprio da escrita filosófica, que é a representação/apresentação da verdade.

A ideia é uma mônada. Sua estrutura é marcada pela totalidade em contraste com seu isolamento. Seu ser mostra a figura abreviada do restante do mundo das ideias, pois nela repousa a representação dos fenômenos como sua interpretação objetiva, ou seja, em cada ideia há contida a imagem do mundo. As mônadas mantem uma relação de mutualidade e reciprocidade umas com as outras.

Analisar a ideia monadologicamente significa ter acesso tanto ao particular como ao todo. E, segundo Benjamin, "a tarefa imposta à sua representação é nada mais nada menos que a do esboço dessa imagem abreviada do mundo"12. Ou seja, em cada ideia encontramos todas as ideias como partes constituintes. Como na mônada, cada ideia contém o particular e o universal.

\footnotetext{
${ }^{11}$ Ainda sobre o conceito de origem vejamos o que nos fala Rouanet: "a ideia de que 'o termo origem não designa o vir-a-ser daquilo que se origina, e sim algo que emerge do vir-a-ser e da extinção', corresponde ponto por ponto à tese de que o historiador dialético deve libertar o objeto histórico do fluxo da história contínua, salvando-o, sob a forma de um objeto-mônada: fragmento de história, agora intemporal, que o olhar de Medusa do historiador mineraliza, transformando-o em natureza, e que como tal dá acesso à pré-história do objeto, e à sua pós-história. Na perspectiva da história descontínua, a única verdadeiramente dialética, não se pode portanto falar em gênese, que supõe o vir-a-ser e o encadeamento casual, e sim em origem, que supõe um salto no Ser, além de qualquer processo". Rouanet, S. P. Apresentação, In: Origem do Drama Barroco Alemão, p. 19.
}

12 BENJAMIN, Origem do drama trágico, p. 37. 


\section{REFERÊNCIAS}

BENJAMIN, Walter. Origem do Drama Barroco Alemão. Trad. Sergio Paulo Rouanet. São Paulo: Ed. Brasiliense, 1968.

. Origem do drama trágico alemão. Trad. João Barreto. Belo Horizonte: Autêntica Editora, 2011.

Sobre a linguagem em geral e sobre a linguagem do homem. In: Escritos sobre mito e linguagem. Or. Jeanne Marie Gagnebin, Trad. Susana Kampff Lages e Ernani Chaves. São Paulo: Duas Cidades; Ed. 34, 2011.

GAGNEBIN, J.M. Do conceito de Darstellung em Walter Benjamin ou a verdade e a beleza. Kriterion: Revista de Filosofia. Vol. 46 no.112. Belo Horizonte, Dec. 2005. 